\title{
Notitie voor de Provincie Limburg naar aanleiding van de workshop 'Human Capital and Regional Development'
}

Citation for published version (APA):

Cörvers, F., \& Hooijen, I. (2017). Notitie voor de Provincie Limburg naar aanleiding van de workshop 'Human Capital and Regional Development'. ROA. ROA Fact Sheets No. 005

https://doi.org/10.26481/umarof.2017005

Document status and date:

Published: 01/01/2017

DOI:

10.26481/umarof.2017005

Document Version:

Publisher's PDF, also known as Version of record

\section{Please check the document version of this publication:}

- A submitted manuscript is the version of the article upon submission and before peer-review. There can be important differences between the submitted version and the official published version of record.

People interested in the research are advised to contact the author for the final version of the publication, or visit the DOI to the publisher's website.

- The final author version and the galley proof are versions of the publication after peer review.

- The final published version features the final layout of the paper including the volume, issue and page numbers.

Link to publication

\footnotetext{
General rights rights.

- You may freely distribute the URL identifying the publication in the public portal. please follow below link for the End User Agreement:

www.umlib.nl/taverne-license

Take down policy

If you believe that this document breaches copyright please contact us at:

repository@maastrichtuniversity.nl

providing details and we will investigate your claim.
}

Copyright and moral rights for the publications made accessible in the public portal are retained by the authors and/or other copyright owners and it is a condition of accessing publications that users recognise and abide by the legal requirements associated with these

- Users may download and print one copy of any publication from the public portal for the purpose of private study or research.

- You may not further distribute the material or use it for any profit-making activity or commercial gain

If the publication is distributed under the terms of Article $25 \mathrm{fa}$ of the Dutch Copyright Act, indicated by the "Taverne" license above, 
Research Centre for Education and the Labour Market | ROA

Notitie voor de Provincie Limburg

naar aanleiding van de workshop

'Human Capital and Regional Development'

Maastricht, 16 en 17 juni 2017

Frank Cörvers

Inge Hooijen

\section{ROA Fact Sheet}

ROA-F-2017/5

Researchcentrum voor Onderwijs en Arbeidsmarkt | ROA Research Centre For Education and the Labour Market / ROA 
Deze notitie biedt enkele potentieel relevante bevindingen voor de Provincie Limburg van de wetenschappelijke studies die gepresenteerd en besproken zijn tijdens de workshop 'Human Capital and Regional Development' op 16 en 17 juni 2017 te Maastricht. De weergave hieronder is een enigszins vrije interpretatie van hetgeen gepresenteerd is, gecategoriseerd naar drie beleidsvelden (ruimtelijk, onderwijs en arbeidsmarkt, sociaaleconomisch).

\section{Ruimtelijk beleid}

\section{Locatiekeuze van personen}

Migratiemotieven verschillen tussen personen. Migratie wordt bijvoorbeeld gedreven door arbeidsmarktfactoren of door de aantrekkingskracht van voorzieningen in een bepaald gebied. Onderzoek aan de Rijksuniversiteit Groningen laat zien dat de impact van deze factoren varieert tussen regio's in Nederland. Dit onderzoek wijst op het belang van de regionale context in het anticiperen en ontwerpen van regionaal beleid in relatie tot de dynamiek van de bevolking. Generieke beleidslijnen gebaseerd op algemene of gemiddelde resultaten kunnen in de praktijk dus leiden tot verschillende uitkomsten. Dit is bijvoorbeeld afhankelijk van de kenmerken van de lokale bevolking en arbeidsmarkt. Het is hier van belang om van een 'placeneutral' aanpak toe te werken naar een 'place-based' aanpak.

Een voorbeeld van bovengenoemde aanpak is het onderzoek naar de woonwensen van technische kenniswerken op de Chemelot Campus (zie ook Structuurvisie Wonen Zuid-Limburg (SVWZL, 2016, p.50). Op basis van een tevredenheidschaal vindt deze studie o.a. dat de technische werker (vergeleken met een niet-technische werker) minder gelukkig wordt als de woon-werk afstand stijgt, waarbij faciliteiten en voorzieningen een kleine rol lijken te spelen voor hun geluk. De resultaten van de gepresenteerde studie laten tevens zien dat de technische werker voornamelijk in de gemeenten rondom de campus woont, bijvoorbeeld in Beek, Stein of Sittard-Geleen. Deze gemeentes worden volgens de indeling van het $C B S$ gezien als suburbane of rurale gebieden. De match tussen de woonwensen en het daadwerkelijk woongedrag is niet altijd goed. De woonvoorkeuren en het uiteindelijke woongedrag vertonen een wisselwerking, ook in genoemd onderzoek. Het beeld dat personen hebben bij de woonwensen is vaak incompleet. Mensen zijn bijvoorbeeld geneigd om de woonwensen aan te passen aan het woningaanbod, de financiële situatie en de wensen van een eventuele partner (voor een voorbeeld zie ook De triomf van de stedelijke voorkeur, PBL, 2017).

In het Provinciaal Omgevingsplan Limburg (POL) van 2014 wordt de nadruk gelegd op grootschalige ontwikkelingen in de steden en wordt het contrast aangesneden tussen meer stad, meer land. Het SVWZL (2016) legt de nadruk op subgroepen, zoals expats, kenniswerkers, arbeidsmigranten en studenten. Ook hier is het echter niet vanzelfsprekend dat deze doelgroepen de voorkeur geven aan stedelijke gebieden als woonomgeving. Veel onderzoek richt zich op urbane gebieden en is relatief vaak gebaseerd op Amerikaanse gegevens. De Europese en Nederlandse context is echter lastig vergelijkbaar met de Amerikaanse context. Relevant zou zijn om verder onderzoek te doen naar de woonwensen en het daadwerkelijk woongedrag binnen Limburg.

\section{Regionale mobiliteit}

Voor hogere opgeleide afgestudeerden geldt dat er groepen kunnen worden onderscheiden met een bepaald mobiliteitspatroon, zoals mobiel en immobiel, of lange- of korte-afstandspendelaar. Zo zijn afgestudeerde WO'ers vaker mobiel dan afgestudeerde HBO'ers. De woon-werkafstand is de afgelopen jaren toegenomen en het zijn voornamelijk hoogopgeleiden die lange afstanden afleggen. Dit biedt tevens meer keuzevrijheid in de woon- of werkplek voor mensen. Wel vinden de meeste pendelstromen plaats in de Randstad en zijn de pendelstromen aanzienlijk lager in bijvoorbeeld de provincies Zeeland, Groningen, Friesland en Limburg (zie bijvoorbeeld De geografie van het werken in Nederland verandert, PBL, 2016).

Binnenlandse migratie en pendel lijken substituten te zijn. Hoewel er regio's zijn die per saldo verliezen of winnen, zijn de inkomende en uitgaande mobiliteit tussen regio's met elkaar gecorreleerd. Toch is nog ruim de helft van de afgestudeerden niet mobiel. Mobiliteit is groter in regio's met een kleine baandichtheid, maar persoonskenmerken (opleidingsniveau en -richting, geslacht, leeftijd, etc.) spelen allemaal een rol. Eenmaal mobiel geweest, vergroot de kans op daarop volgende mobiliteit.

Volgens de neo-klassieke theorie verkleint de mobiliteit de verschillen tussen regio's. Volgens het roltrapmodel, waarbij mobiliteit wordt gebruikt om op te klimmen op de sociale ladder, blijven de regionale mobiliteitspatronen min of meer stabiel. Theorieën die uitgaan van agglomeratievoordelen resulteren in grotere regionale verschillen, omdat er 
bijvoorbeeld telkens meer hogere opgeleiden naar dezelfde regio's trekken. Dit wordt ook wel 'brain drain' en 'brain gain' genoemd oftewel de trek van het platteland naar de urbane gebieden met een hogere werkgelegenheid.

\section{Hoger opgeleiden kunnen hun arbeidsmarktpositie} verbeteren door te verhuizen c.q. in een andere regio te gaan werken. In de economische en juridische opleidingen zijn het vooral de betere studenten die naar de Randstad trekken Duidelijk is dat baankansen uitgedrukt in werkloosheid en loonniveau van een regio voor hoger opgeleiden belangrijker zijn dan woonkenmerken. Woonkenmerken gerelateerd aan regionale cultuur, kwaliteit van leven en voorzieningen kunnen echter ook een rol spelen bij de mobiliteitsbeslissingen en locatiekeuze. Voor kleine groepen huizenbezitters is etnische diversiteit in een buurt een 'asset'. Laatstgenoemde voorbeelden spelen zeker een belangrijke rol wanneer de keuze voor het werk eenmaal gemaakt is. In de literatuur worden dit ook wel de 'zachte locatiefactoren' genoemd.

Conclusie van de gepresenteerde onderzoeken is dat baankansen erg belangrijk zijn voor de vestiging van (hoger opgeleide) werkenden, maar dat er ook maatwerk is vereist om de tevredenheid voor de binnen- en buitenlandse (hoogopgeleide) migranten qua woonomgeving en leefklimaat hoog te houden

\section{Krimp en voorzieningen}

In het debat rondom krimpvraagstukken wordt vaak gesuggereerd dat bevolkingsafname hand in hand gaat met de afname van faciliteiten en voorzieningen. De voorzieningen zoals lokale supermarkten, onderwijs en gezondheidszorg staan vaak hoog op de agenda van ruimtelijk beleid. Onderzoek van de Rijksuniversiteit Groningen laat de veranderingen zien in de verdeling van lokale faciliteiten voor de basisbehoeften in de provincie Friesland. De resultaten geven weer dat de verdeling van voorzieningen verandert, met de sterkste daling in de kleine dorpen. Echter, door de dichtheid van de basisfaciliteiten en door toenemende mobiliteit blijft de toegankelijkheid goed. Bovendien blijken er personen en gezinnen te zijn die recent zijn komen wonen in de gebieden met weinig voorzieningen. De afname van het aantal voorzieningen lijkt dus niet altijd af te schrikken bij de locatiekeuze.

Interessant is dat de grote veranderingen in faciliteiten niet per se overeenkomen met de door de overheid vastgestelde (krimp)gebieden. De overheid zou zich moet richten op de gebieden met een lage mobiliteit met de overige regio's in plaats van zich te richten op specifieke krimpgebieden. Dit is een interessante aanpak voor onderzoek in Limburg.

\section{Een euregionaal perspectief}

Eén van de gepresenteerde onderzoeken gaat over de mobiliteitswensen van studenten aan hogere beroepsopleidingen en academische opleidingen binnen de euregio Maas-Rijn (EMR). De resultaten van dit onderzoek laten zien dat het grootste gedeelte van de ondervraagde studenten de EMR willen verlaten na afstuderen of nog niet zeker zijn over hun keuze. Onder de studenten die willen blijven is het grootste percentage ook geboren binnen de EMR en zijn ze minder vaak verhuisd voor de studie vergeleken met de groep die niet zeker is over de verhuizing of verwacht te vertrekken uit de regio. Dit benadrukt de zogenaamde 'thuisvoorkeur' en 'regionale bekendheid' bij het kiezen van een woonplaats.

De intentie om weg te trekken uit de regio wordt veroorzaakt door de wisselwerking tussen verschillende economische, sociale en culturele factoren. Bovendien beïnvloeden afstand tot de partner en andere sociale banden zoals familie en vrienden migratie-intenties van deze doelgroep. In vergelijking met de perceptie over de werkmogelijkheden lijken factoren zoals openheid, tolerantie en sociale factoren een krachtigere verklaring te hebben in de verhuisintentie. De resultaten van dit onderzoek komen overeen met het grootschalige Europees onderzoeksproject (ACRE) dat zich o.a. richt op locatiekeuzes binnen de Europese context. Interessant is dat dezelfde processen een rol spelen bij het bepalen van de mobiliteitsintenties aan alle kanten van de grens. Programma's op euregionaal niveau om toekomstige afgestudeerden te behouden kunnen daarom worden aanbevolen. Respondenten die niet in de EMR wonen tijdens hun studie wonen waarschijnlijk ook niet in de toekomst in de EMR.

Een suggestie om de EMR beter te profileren is het aanbieden van aantrekkelijke en betaalbare woningen voor studenten. Woonervaring opdoen in de EMR biedt studenten concrete informatie over carrièremogelijkheden en ervaringen die verband houden met de kwaliteit van het leven, zoals culturele en vrije tijdsactiviteiten aan alle zijden van de grenzen. Het bevorderen van informatie voor baanmogelijkheden en uitwisselingsprojecten binnen de euregio kan de kans vergroten om mensen te binden na het afstuderen.

\section{Onderwijs- en arbeidsmarktbeleid}

\section{Opleiding}

Hoger opgeleiden verdienen een hoger loon en zijn minder vaak werkloos, hebben een betere gezondheid en een hogere levensverwachting dan lager opgeleiden. Alle werknemers dragen bij aan de economische groei: het maatschappelijk rendement is ongeacht het opleidingsniveau ongeveer even groot voor alle werknemers. Het private rendement (het loon) is veel hoger voor de hoger dan voor de lager opgeleiden, waarbij ook lager opgeleiden er voordeel van hebben als ze in een omgeving werken met veel hoger opgeleiden. De conclusie is dat het altijd goed is voor een regio om te investeren in de opleiding van de bevolking. Toch is er ook twijfel: de robotisering, en meer in het algemeen de technologische 
ontwikkeling ('skill-biased technological change', SBTC), kan ertoe leiden dat meer investeringen in onderwijs helemaal niet meer lonen voor grote groepen, en dat er grotere ongelijkheden gaan ontstaan tussen een kleine groep rijken en veel armen (in navolging van Piketty).

Geletterdheid van de bevolking is ook een belangrijke factor voor de economische ontwikkeling. Het is daarom belangrijk om de laaggeletterdheid op regionaal en zelfs op gemeentelijk niveau in kaart te brengen. Probleem daarbij is dat er onvoldoende gegevens zijn op dit detailniveau. Daarom is in één van de gepresenteerde onderzoeken de laaggeletterdheid op gemeenteniveau geschat door verschillende bestanden te koppelen en daarbij gebruik te maken van een nieuwe econometrische methode ('small area estimation'). In deze methode worden de statistische correlaties op landelijk niveau benut tussen enerzijds laaggeletterdheid en anderzijds de hulpvariabelen opleiding, herkomst, arbeidsparticipatie en beroepsstatus, om daarmee vervolgens de laaggeletterdheid op gemeenteniveau (waarvoor laaggeletterdheid niet bekend is maar de hulpvariabelen wel) te schatten. Deze methode kan ook op andere terreinen gebruikt worden om betrouwbare informatie op regionaal of gemeentelijk niveau te genereren. Dit gebeurt overigens al door het Centraal Bureau voor de Statistiek (CBS) om de werkloosheid op gemeenteniveau te schatten.

\section{Werkloosheid}

Individuen die werkloos zijn geweest bij het schoolverlaten hebben een grotere kans op hernieuwde werkloosheid en een lager loon later in hun leven, in het bijzonder bij de lager opgeleiden. De duur van de werkloosheid, de periode en de regio spelen daarbij een rol voor de grootte van dit effect. Een moeilijk te beantwoorden vraag is of dat komt door de karakteristieken van deze personen of door 'scarring' vanwege de achterstand die men oploopt door een periode niet te werken (en dus niet te investeren in het eigen menselijk kapitaal door formele en informele training 'on-the-job').

Verder blijkt het in Duitsland mogelijk om werklozen door geldelijke vergoedingen (bijv. een verhuisbonus) te stimuleren om ook in verder weg gelegen regio's te solliciteren op vacatures. Dit leidt tot meer verhuizingen, betere arbeidsmarktvooruitzichten, een hoger inkomensniveau en betere baankansen voor de partner. Omgekeerd zou het dus voor afgelegen regio's, zoals Limburg vanuit nationaal perspectief, voordelig (voor Nederland en de eigen regio) kunnen zijn om werklozen van buiten de regio aan te trekken en aan het werk te helpen met dergelijke instrumenten.

Eén van de gepresenteerde studies onderzoekt de impact van regionale en buurtkenmerken op het risico dat jonge niet-westerse immigranten werkloos worden na het afronden van een MBO-opleiding in Nederland.
Buurteffecten onder immigranten ontstaan door de vorming van sociale normen en socialisatie, regio-effecten betreffen de kansen op regionaal niveau. Adolescente immigranten van niet-westerse herkomst hebben een hogere kans werkloos te worden in economisch achtergestelde regio's. Vooral dan laten gebrekkige informatie over baankansen en discriminatie zich voelen. In urbane gebieden zijn hun werkgelegenheidsvooruitzichten echter beter als er veel co-etnische inwoners in de buurt zijn. Daarbij kan wel de baankwaliteit (beloning, training, contractduur) een probleem vormen.

\section{Sociaaleconomisch beleid}

\section{Sociaaleconomische ontwikkeling}

Als het gaat om het stimuleren van de regionale economische ontwikkeling, is het vaak de vraag of er geïnvesteerd moet worden in meer dichtbevolkte gebieden en grotere steden of ook in spreidingsbeleid gericht op de omliggende en randgebieden. Grotere steden leveren een hogere productiviteit per persoon op dan de kleinere, hebben meer voorzieningen, maar hebben ook hogere landen huizenprijzen en vaker een slechte luchtkwaliteit, meer congestie en een grotere onveiligheid.

In de keynote lezing is er verder ingegaan op de typering van verschillende soorten steden en regio's en de stereotypering van personen die daar wonen. $43 \%$ van de urbane gebieden in de OECD kenmerkt zich door vergrijzing en langzame economische groei. $29 \%$ van de urbane gebieden heeft veel jongeren maar vergrijst snel, en $28 \%$ van de urbane gebieden heeft een jonge populatie en vergrijst langzaam. Regio's met veel voorzieningen en vrijetijdsindustrie zijn over het algemeen meer vergrijsd, met steeds hogere inkomens en welvaart. Dat laatste geldt ook voor de open en dynamische regio's met hoge koopkracht en veel immigratie. Oude industriegebieden en afgelegen rurale regio's laten daarentegen vergrijzing en bevolkingsdeling zien door vertrek van jongeren en hoogopgeleiden.

Regionaal overheidsbeleid kan volgens een studie van de Erasmus Universiteit invloed uitoefenen op de regionale ontwikkeling via een diversificatiebeleid van de regionale economie. Terwijl eerder onderzoek van het Planbureau van de Leefomgeving (PBL) laat zien dat meer diversificatie samenhangt met een grotere veerkracht van een regio, wordt in deze studie ingegaan op hoe formele en informele instituties via specialisatie ('density') en verwantschap tussen activiteiten ('relatedness') het aanpassingsvermogen en de innovatie kunnen beïnvloeden. Om nieuwe producten en diensten te ontwikkelen en innovaties mogelijk te maken wordt het van belang geacht dat er in een regio al voldoende verwante economische activiteiten zijn. Formele instituties spelen daarbij een rol. Dit zijn regels, wetten en instellingen, die weliswaar geen directe invloed hebben op innovatie, maar wel kunnen zorgen voor voldoende 
specialisatie in economische activiteiten en de innovatie in verwante producten en diensten kunnen stimuleren. Hierbij dient de regionale kracht van de specialisatie als basis voor succesvolle diversificatie in verwante economische activiteiten.

\section{Sociaal kapitaal}

Informele instituties zijn eveneens van belang voor de regionale ontwikkeling. Hieronder worden verstaan sociale normen en gebruiken, welke het sociaal kapitaal in een regio vormen. Vooral bij zwak bestuur is het sociaal kapitaal in een regio van belang. Er wordt bij sociaal kapitaal onderscheid gemaakt tussen meer intern gericht sociaal kapitaal ('bonding' door bijv. vakbonden, beroepsorganisaties en politieke partijen), extern gericht sociaal kapitaal ('bridging' door bijv. culturele instellingen en jeugdwerk) en vertrouwen. De laatste twee vormen van sociaal kapitaal zijn belangrijk voor succesvolle diversificatie. Formele instituties zijn belangrijk om de specialisatie te bevorderen en een te grote, eventueel stagnerende invloed van gevestigde belangen ('bonding') te voorkomen.

Hierop aansluitend lijkt er een onderbouwing te zijn voor de bemoeienis van regionale overheden om campussen te ontwikkelen die de specialisatie bevorderen maar van daaruit ook diversificatie en innovatie in verwante activiteiten proberen te sturen. Regionale beleidsmakers dienen op te letten dat de gevestigde belangen niet een te grote macht krijgen omdat dit innovatie en verdere economische ontwikkeling kan belemmeren. De vraag blijft wel hoe in een regio het sociale kapitaal in de vorm van 'bridging' (in eigen woorden: 'bruggen slaan') en vertrouwen gestimuleerd kan worden.

In de keynote lezing werd verder ingegaan op de 'Geography of Discontent' (gerelateerd aan vertrouwen). Hierbij is op regionaal niveau gekeken naar de relatie tussen aan de ene kant Brexit en populisme (in UK en diverse andere landen) en aan de andere kant globalisering (belang export en industrie voor de regio), regionale leeftijds- en opleidingssamenstelling, welvaart en urbaniteit. Er lijken wel verbanden te zijn maar duidelijke conclusies ontbreken nog waardoor verder onderzoek naar de mechanismen en de mogelijke verklaringen van de empirische verbanden gewenst is.

\section{Overzicht van presentaties in workshop}

- Jouke van Dijk (University of Groningen), Inequalities in Human Capital, Regional Development and Well-being

- Frank van Oort (Erasmus University Rotterdam), Nicola Cortinovis, Jing Xiao and Ron Boschma, Quality of Government and Social Capital as Drivers of Regional Diversification in Europe

- Marten Middeldorp (University of Groningen), Arjen Edzes and Jouke van Dijk, Job access, Spatial Mobility and Early Career Success

- Julia Reinold (Maastricht University), Inge Hooijen, Christoph Meng and Melissa Siegel, Competition for Talent: Retaining Graduates in the Euregio Meuse-Rhine

- Philip McCann (Sheffield University), Urban Futures, Population Ageing and Demographic Decline, keynote lecture

- Inge Hooijen (Maastricht University) and Frank Cörvers, How to Attract STEM Workers to a High-tech Business Park in a Shrinking Region? Place and Life Satisfaction

- Richard Rijnks (University of Groningen), Sierdjan Koster and Philip McCann, Spatial Heterogeneity in Amenity and Labor Market Migration

- Jessie Bakens (Maastricht University) and Thomas de Graaff, Valuation of Ethnic Diversity: Heterogeneous Effects in an Integrated Labor and Housing Market

- Ronald McQuaid (University of Stirling), Long-term Scarring Effects of Unemployment and a Poor Job Start for Young People

- Hugh Lauder (University of Bath) and Phillip Brown, The Fractured Relationship between Education and the Labour Market: The End of the Human Capital/Skill Bias Research Programme?

- Katarina Wessling (University of Cologne) and Christoph Meng, Assessing the Influence of Neighborhoods and Regions Simultaneously: Unemployment Risk of Young Immigrants in the Netherlands

- Steffen Künn (Maastricht University), Marco Caliendo and Robert Mahlstedt, Mobility Assistance for Unemployed Workers, Job Search Behavior and Labor Market Outcomes

- Ineke Bijlsma (Maastricht University), Jan van den Brakel, Rolf van der Velden and Jim Allen, Estimating Literacy Levels at a Detailed Regional Level: An Application Using Dutch Data

- Suzan Christiaanse (University of Groningen), The Relativity of Rural Deprivation: Changes in Distribution and Access to Basic Facilities in Fryslân, Netherlands 
$6 \quad$ Notitie - Provincie Limburg

Colofon

(C) Researchcentrum voor Onderwijs en Arbeidsmarkt (ROA). Niets uit deze uitgave mag op enige manier worden verveelvoudigd zonder voorafgaande schriftelijke toestemming van de directeur van het ROA.

Researchcentrum voor Onderwijs en Arbeidsmarkt

Postbus 616

6200 MD Maastricht

$\mathrm{T}+31433883647$

$F+31433884914$

secretary-roa-sbe@maastrichtuniversity.nl

www.roa.nl

Maastricht University

School of Business and Economics

Vormgeving

ROA secretariaat, Maastricht

september 2017

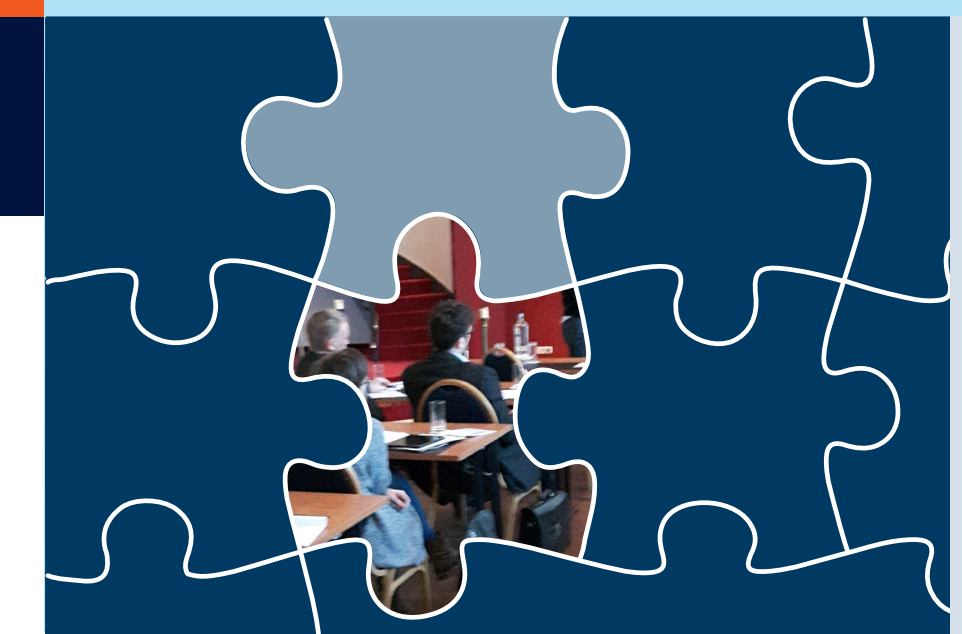

ROA

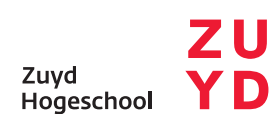

Hogeschool
W O R K S H O P

$16.06 / 17.06$ HUMAN CAPITAL AND REGIONAL DEVELOPMENT

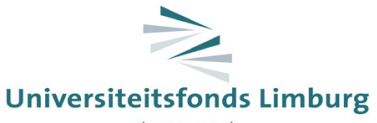
| SWOL |

\section{Maastricht University}

Institute for Transnational and Euregional cross border cooperation and Mobility / ITEM

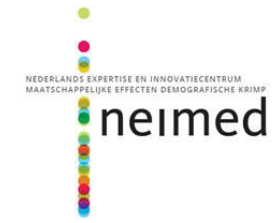

provincie limburg

gesubsidieerd door de Provincie Limburg
Limburg

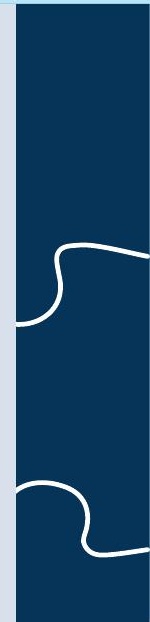

